\title{
Profissionais do Serviço Funerário e a Questão da Morte
}

Funerary Service Professionals and the Death Issue

Professionales del Servicio Funerario y la Cuestión de la Muerte

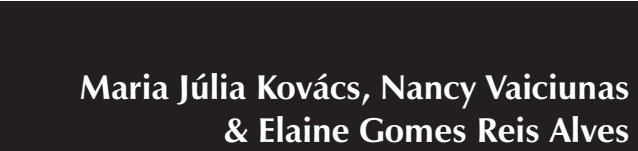

Universidade de São Paulo

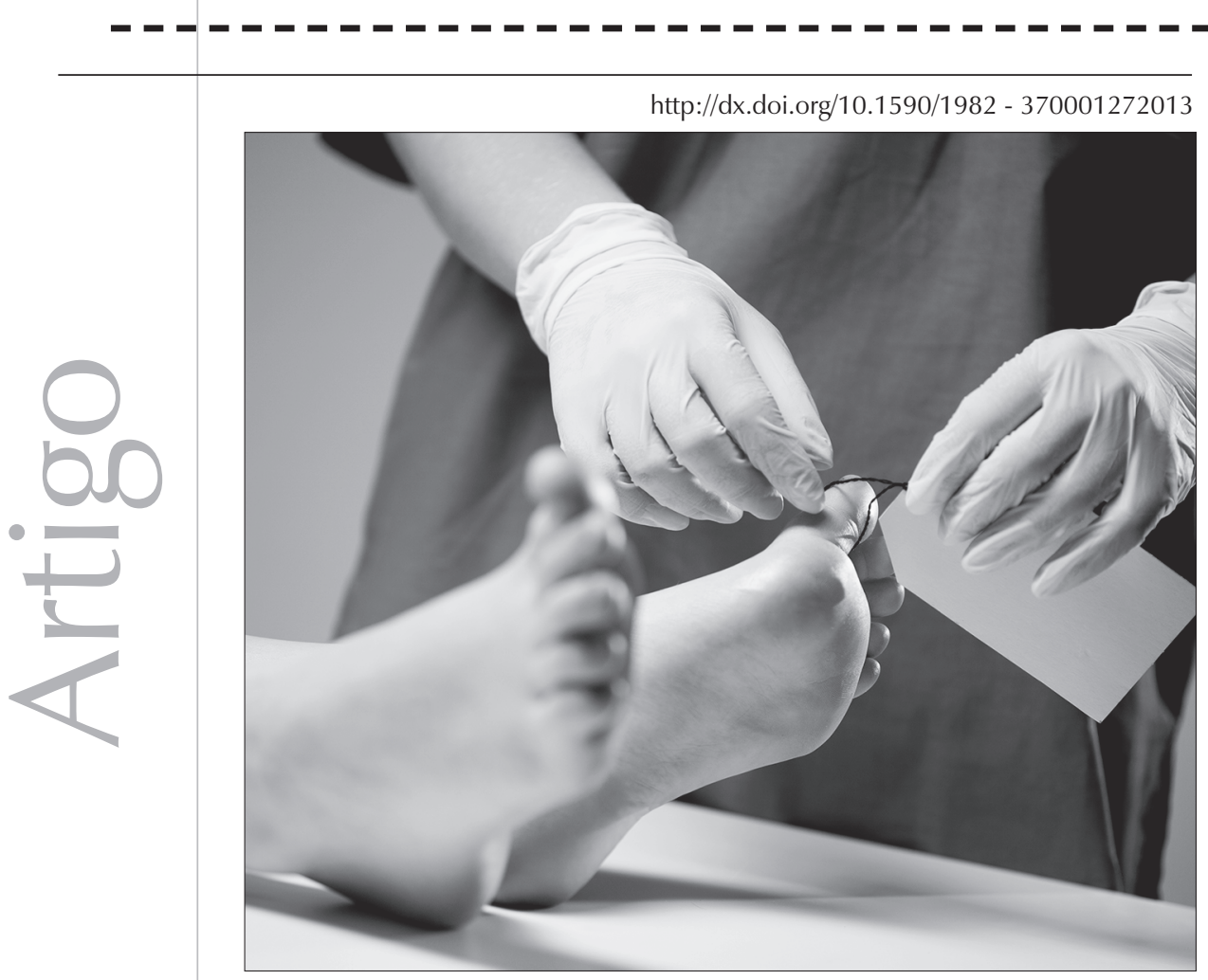


Resumo: Este artigo aborda a questão da morte no cotidiano de trabalho de profissionais funerários. Profissionais de funerária têm condições de trabalho com risco físico e psíquico com possibilidade de desenvolvimento de burnout. Há sobrecarga de trabalho, contato com famílias enlutadas, sem ter preparo para essas tarefas. Não escolheram sua profissão, não têm capacitação nem órgão de classe que os represente. São vistos com desconfiança quando os trabalhos são cobrados ou há demora para realizar os trâmites necessários. São analisados fatores que podem tornar seu trabalho difícil: mortes violentas, suicídio, corpos deteriorados e crianças. Consideramos esses profissionais como cuidadores do corpo morto e de famílias enlutadas. São discutidas formas de cuidados a esses profissionais: luto, famílias, expressão de sentimentos e rituais, e também responder às questões pessoais. Foram oferecidas informações e esclarecimentos sobre modalidades de cuidado pessoal e psicológico.

Palavras-chave: Morte. Educação em relação à morte. Atitudes frente à morte. Ritos de morte.

Abstract: This paper deals with the death issue in funerary workers' everyday work. Funerary professionals have work conditions of physical and psychic risks with the possibility of burnout development. There is work overload, contact with the mourning families without training for those tasks. They did not choose their profession; they do not receive capacity building or class representation. They are regarded with mistrust when there are charges on the work or if there is time lag to carry out needed courses. Factors that may turn their work difficult are analyzed: violent deaths, suicides, deteriorated corpses, and children. We consider those workers as caretakers of the dead and of mourning families. Ways of caring for those professionals are discussed: mourning, families, expression of feelings and rituals, and responding to personal questioning as well. Information and clarifications were provided on modalities of personal care and psychological attention.

Keywords: Death. Education related to death. Attitudes in face of death. Death rites.

Resumen: Este artículo aborda la cuestión de la muerte en el cotidiano de trabajo de profesionales funerarios. Profesionales de funeraria tienen condiciones de trabajo con riesgo físico y psíquico con posibilidad de desarrollo de burnout. Hay sobrecarga de trabajo, contacto con familias de luto, sin tener preparación para estas tareas. No escogieron su profesión, no tienen capacitación, ni órgano de clase que los represente. Son vistos con desconfianza cuando los trabajos son cobrados o hay demora para realizar los trámites necesarios. Son analizados factores, que pueden tornar su trabajo difícil: muertes violentas, suicidio, cuerpos deteriorados y niños. Consideramos a estos profesionales como cuidadores del cuerpo muerto y de familias de luto. Son discutidas formas de cuidados a estos profesionales: luto, familias, expresión de sentimientos y rituales, y también responder a las cuestiones personales. Fueron ofrecidas informaciones y esclarecimientos sobre modalidades de cuidado personal y psicológico.

Palabras-clave: Muerte. Educación en relación a la muerte. Actitudes frente a la muerte. Ritos de muerte. 
Há poucas referências na bibliografia especializada em tanatologia envolvendo o trabalho de profissionais de serviços funerários em relação à morte. Realizamos a busca de artigos sobre profissionais de serviços funerários nas bases de dados e em periódicos especializados na área de estudos sobre a morte, como o Omega, Journal of Death and Dying e Death Studes nos anos de 2009-2012, e não encontramos nenhum artigo sobre $\mathrm{O}$ tema. Entrando no indexador Scielo com os termos profissionais de funerária ou agentes funerários, não encontramos nenhum artigo. Com os unitermos trabalhadores da morte, foram encontrados 15 artigos, todos sobre profissionais de saúde e nenhum sobre os profissionais de serviços funerários. Com o termo morte sem outro qualificativo, encontramos 2.922 artigos e nenhum sobre o tema deste estudo. A relevância do tema e a pouca literatura encontrada motivou-nos a escrever este trabalho. Tomamos como base também o curso "Morte e os profissionais do Serviço Funerário do Município de São Paulo", coordenado e ministrado pelas autoras deste artigo em uma parceria entre o Laboratório de Estudos sobre a Morte do Instituto de Psicologia da Universidade de São Paulo (USP) e o Serviço Funerário do Município de São Paulo.

\section{Retratos da morte}

O desenvolvimento da tanatologia ocorreu em meados do século XX (Kovács, 2008). Hermann Feifel, em 1959, escreveu o clássico The meaning of death, estimulando um movimento de conscientização da morte em meio à mentalidade de interdição sobre o tema. Esse livro inclui capítulos de autores que foram pioneiros na área da tanatologia, entre os quais Glaser e Strauss, cujo capítulo: Awareness of dying, no qual discutem a consciência da morte em pacientes terminais e Schneidman e Farberow, nessa mesma obra escreveram o capítulo sobre prevenção do suicídio.
Kastenbaum e Aisenberg apresentam, em 1983, o livro Psicologia da Morte, referência na área da tanatologia. Esses autores organizaram bibliografia sobre o tema e, na década de 1970, criaram um periódico especializado na área da tanatologia, o Omega Journal of Death and Dying, clássico para os estudiosos da área.

Na década de 1960, houve grandes mudanças na área de estudos sobre a morte, como atestam os trabalhos de Elisabeth KüblerRoss e Cicely Saunders, que revolucionaram o trabalho com pacientes em estágio terminal da doença, ao trazer o tema da morte a público, desafiando a mentalidade que propunha a morte como tema interdito (Ariès, 1977).

No Brasil, o impulso para o desenvolvimento dessa área se deu com Wilma Tôrres, que criou o programa pioneiro "Estudos e Pesquisas em Tanatologia", no Isop/Fundação Getúlio Vargas, no Rio de Janeiro, em 1980, com o intuito de realizar pesquisas sobre o tema da morte e publicar os relatórios destas. Também, em conjunto com três psicólogas, ministrou o primeiro curso sobre o tema da morte para profissionais de saúde. Organizou o setor de documentação e consultoria, que chegou a reunir 2.000 fichas em 44 entradas, na década de 1970, em que ainda não havia Internet. Essas fichas com referências bibliográficas completas encontravam-se em arquivo de aço aberto para consulta dos interessados na área. Entre os temas presentes: medo da morte, morte e religião, atitudes frente à morte, suicídio, luto, pacientes terminais, morte e desenvolvimento humano, entre outros (Kovács, 2003, 2008).

Ariès (1977), em sua obra História da morte no Ocidente, refere-se a vários retratos da morte. A morte domada, como denominada pelo autor, é evento público e social, faz parte da vida e a possibilidade de comunicação e expressão da dor e sentimentos são 
valorizados. A pessoa doente e próxima da morte não é isolada e os espaços de cuidados e rituais são coletivos.

Atualmente, observa-se interdição da expressão da morte, em que os sentimentos de pesar e tristeza precisam ser contidos. A expressão do luto agride as pessoas e é camuflado. Percebe-se a solidão dos moribundos, nos quartos de hospitais, com horários de visita reduzidos, como aponta Elias (2001). Por essa razão, os rituais de despedida e aproximação da morte ficam impedidos. Como o empenho é principalmente no prolongamento da vida, a morte é vista como intrusa, a presença dos familiares, as despedidas e a comunicação sobre esse tema são condenadas. Diante de uma morte anunciada, muito se preza determinados procedimentos, como exames e cirurgias, travando-se uma luta sem sentido que exaure o paciente, levando-o ao sofrimento com todas essas intervenções. A família assiste, muitas vezes, impotente, a todo esse esforço da equipe sem conseguir conversar e prestar cuidados a seus doentes. Mesmo sendo informados de que está sendo feito o que é possível, os familiares têm a impressão de não estar oferecendo os melhores cuidados ao seu parente doente. O empenho principal é orientado para técnicas de manutenção de índices fisiológicos e não nos cuidados no final da vida e qualidade de morte. Essa interdição é estendida também aos ritos funerários, como veremos a seguir. A morte interdita na sociedade contemporânea ocorre principalmente no âmbito pessoal. Segundo nosso ponto de vista, o motivo desse interdito está relacionado ao temor de causar dor e sofrimento.

Morte escancarada é a morte que invade o cotidiano das pessoas, principalmente nas grandes metrópoles, nas cenas de violência na rua, casas e escolas, ocupando espaço. Por ser invasiva, dificulta proteção e controle, deixando suas vitimas expostas e sem defesas, a comunicação fica truncada e não se conhecem antídotos (Kovács, 2003). São mortes violentas e têm tido aumento significativo nas cidades. Homicídios, acidentes e suicídios atingem principalmente os jovens. Por serem eventos imprevisíveis, sem controle, provocam vulnerabilidade. Atingem pobres e ricos, homens e mulheres, podem vitimar indivíduos ou toda uma comunidade. Muitas mortes violentas ocorrem nas escolas ou próximo a elas.

Os rituais são fundamentais para dar sentido e significado a situações de crise, e a morte se enquadra aí. O ritual de velório teve sua origem na necessidade de confirmar a morte, quando, no passado, pela condição científica da época, era difícil reconhecer a morte e podia acontecer de pessoas despertarem estando já enterradas, confirmando um dos maiores medos da humanidade, que o é de ser enterrado vivo. O velório é também ritual de despedida com o corpo presente, tão importante para aqueles que não estiveram por ocasião da morte da pessoa. Atualmente, não há necessidade de aguardar a morte como definitiva porque o atestado de óbito é sua confirmação. O espaço de despedida e reunião de familiares e amigos, a preparação do corpo no caixão, as velas, coroas são responsabilidade dos velórios, e na sua versão luxuosa estão os "funeral homes", que já começam a se estabelecer no Brasil. Essas instituições foram caracterizadas na obra de Mitford (1963), The american way of death, citada por Ariès (1977), tiveram sua origem e se tornaram populares nos Estados Unidos. Sua principal função é tirar da família a tarefa de cuidar de seus mortos. Nos "funeral homes", busca-se fazer com que mortos pareçam vivos e a impressão de que a morte não ocorreu.

Há povos que sempre veneraram seus mortos, como é o caso dos egípcios, que se aprimoraram na técnica de conservá-los pelo em- 
balsamento e pelas construções das pirâmides tão conhecidas.

Os rituais funerários são muito importantes porque a convivência entre vivos e mortos nem sempre é pacífica, como exemplifica Ariès (1977). As almas penadas, os espíritos que assombram as pessoas e mais concretamente há a possibilidade de contaminação do solo, o que promoveu a regulamentação dos cemitérios, vigente nos dias atuais. Então, os rituais têm como propósito, para os religiosos, o descanso da alma e, para os enlutados, a certeza de que os mortos repousam em paz. Em nossa opinião, um dos motivos pelos quais os profissionais funerários são estigmatizados é seu contato cotidiano com corpos mortos.

Outro ritual importante em várias épocas é o enterro. Neste trabalho, são protagonistas os sepultadores, anteriormente conhecidos como coveiros. Muitos enterros são acompanhados de grande emoção, sinalizando a concretização da morte e o local em que o corpo e a memória da pessoa se fazem presentes. A participação em rituais significativos ajuda na elaboração do luto e na construção de significados na vida sem a pessoa amada.

Na morte interdita, os rituais perdem seu lugar de significado. Diminui-se o tempo do velório e os enterros são cada vez mais rápidos. É importante considerar que os rituais estão ligados a uma dada cultura e é muito importante que sejam respeitados também os costumes e valores, o que, muitas vezes, não acontece, principalmente com migrantes e imigrantes.

A busca da boa morte implica em cuidados para alívio e controle de sintomas e a proximidade de pessoas significativas, e os rituais de final de vida, despedidas, asseguram, dentro do possível, os desejos da pessoa à morte, inclusive no que se refere à disposi- ção do corpo, na terra, na cremação e também para o destino das cinzas. Para os familiares, a expectativa e realizações do que entendem por boa morte ajudam na elaboração do luto, incluindo também as tarefas pós-morte, os rituais de velório, cerimônias de corpo presente e o cuidado no enterro ou cremação.

\section{Trabalhadores da morte, profissionais funerários, estresse e burnout}

Os agentes funerários, conhecidos como trabalhadores da morte, também estão na categoria de profissionais que vivem situações de estresse prolongado e podem apresentar a síndrome laboral do "burnout". Não têm seu trabalho valorizado, nem pessoalmente nem financeiramente. Mais do que isso, vivem a rejeição social, estendida a seus familiares, fato observado também por Souza e Boemer (1998), Farina et al. (2009) e Câmara (2011). Esses profissionais têm risco de adoecimento e esgotamento físico e mental por não terem capacitação e preparo, falta de materiais adequados, baixa remuneração e pouco reconhecimento e valorização do trabalho. É queixa frequente a sobrecarga de trabalho, sem descanso, pois há ausências, faltas, aposentadoria e não reposição de profissionais. Os serviços funerários públicos têm de funcionar 24 horas, todos os dias do ano. Há também um número crescente de enterros a serem realizados em certas épocas, o que impede aos sepultadores e outros profissionais funerários o contato com a família. Os profissionais funerários constituem-se assim como um grupo de profissionais em situação frequente de vulnerabilidade física e psíquica.

Os trabalhadores da morte, como apontado por Ruiz e Cavalcante (2007), citados por Câmara (2011), trazem às pessoas a materialização da dor e o fato da morte. Uma 
das situações mais penosas é quando a terra da pá cai sobre o caixão, iniciando o processo de sepultamento. É como se aí se encerrasse o processo de velamento. Não há mais corpo, só os sentimentos diante da ausência. Algumas famílias enlutadas manifestam seus sentimentos de dor, tristeza e raiva diretamente aos profissionais funerários, que por sua vez não compreendem esta torrente de sentimentos e podem revidar, criando assim condições constrangedoras. Esses profissionais representam a concretude da morte, a de que não há nada mais que possa ser feito. Lidar com pessoas enlutadas é aspecto essencial a ser considerado na formação dos profissionais funerários.

Farina et al. (2009) realizaram estudo com agentes funerários (sepultadores, veloristas, agenciadores, maquiadores, motoristas) da Grande São Paulo com o objetivo de explorar o cotidiano de trabalhos desses profissionais verificando implicações psicossociais, as dificuldades apresentadas no trabalho e suas experiências marcantes. Os autores organizaram os depoimentos em três eixos: início da profissão, cotidiano de trabalho e estratégias de enfrentamento.

Os profissionais não escolheram de início essa profissão. Buscavam estabilidade financeira e prestaram o concurso para serem funcionários públicos. O cotidiano deles envolve trabalho que lida com a morte, com seus percalços, sendo o principal cuidar dos mortos, com os preconceitos que essa função provoca. Buscam estratégias de enfrentamento em uma profissão com tantas dificuldades, principalmente quando o morto é uma criança. Os autores verificaram que o tempo de profissão ajuda na adaptação, com maiores possibilidades de aperfeiçoamento, busca de novas técnicas e um novo sentido à própria experiência. Profissionais relataram que seu trabalho leva à humildade e consciência e que o medo da morte diminui. En- tretanto, essa função deixa marcas psicossociais fortes que necessitam de ser cuidadas.

Os trabalhadores funerários lidam com a morte cotidianamente e têm as representações sobre morte relacionadas com sua história de vida, características pessoais, experiências vividas, crenças religiosas e fase do desenvolvimento. São também influenciados pela sua relação e valorização do trabalho. É preciso lembrar que as características da morte e dos familiares enlutados influenciam no trabalho. A questão que se apresenta é: esses profissionais lidam com corpos ou com pessoas mortas? A maneira de ver a situação pode se refletir na forma como eles lidam com seu trabalho.

O trabalho de agentes funerários não é reconhecido. Quando os enterros não podem ser realizados, a sua falta é percebida nas raras situações em que é impedido como em greves ou paralisações. São, às vezes, chamados de papa-defuntos, como se estivessem lá apenas para receber por seu trabalho, aliciando os mortos e não como se fosse esta exatamente sua função. Esses trabalhadores têm direito à remuneração digna, mas não a recebem. Os servidores públicos de funerária bem como os particulares não devem cobrar por seu trabalho? É uma contradição, o serviço é exigido, com qualidade e doação de seus funcionários, mas na hora de cobrar a percepção é que está havendo abuso. O cuidado ao corpo morto e os insumos necessários precisam ser negociados e, como em tantos outros negócios, há honestidade e abusos.

O filme Abutres (Diretor Pablo Trapero, Argentina/Chile, 2010) aponta a situação em que o lado sombrio dos trabalhadores da morte é ressaltado. Sosa (Ricardo Darin) é um "urubu", advogado especializado em acidentes rodoviários. Todos os dias, vai até o local de acidentes rodoviários, setores de 
emergência de hospitais e delegacias procurando clientes. Esse é o lado negro para as vítimas desses urubus e abutres, daí o nome do filme (http://www.adorocinema.com/filmes/filme-180376).

É uma profissão que não tem sindicato que os representa, nem órgão de classe. Não há definição clara de sua profissão. Em funções como no caso dos sepultadores, não há necessidade de formação específica ou cursos de preparo para suas tarefas. Muitos aprendem na prática e podem se colocar em situação de risco justamente por não ter preparo adequado. Podem se deparar com situações realmente degradantes, como corpos deteriorados, nas emergências e desastres em locais de difícil acesso. Correm, portanto, grande risco de saúde física, pela contaminação, e de saúde psicológica, pelas situações insalubres do ponto de vista emocional. Dittmar (1991) realizou estudo com profissionais de funerária, observando uma incidência significativa de transtornos psiquiátricos nesses profissionais, problemas que continuam atuais.

Assim como outros profissionais que lidam com a morte sofrem de estranhamento, os profissionais funerários são submetidos a preconceitos, extensivos aos seus familiares. Alguns profissionais relatam que esse preconceito se estende aos filhos, em uma clara indicação de que há temor de contágio da morte, como se a manipulação do corpo morto ficasse impregnado na pessoa e pudesse contaminar quem dele se aproxima.

A morte traz as diferenças nas classes sociais, que se manifestam também nos rituais, como velórios, nos insumos, como tipos de caixões com vários adereços, nas coroas, no local de enterro, que, se agora não é mais nas igrejas e nos seus pátios, é em cemitérios, parques com paisagens especiais ou em cemitérios verticais com vários requintes, cada um com seu preço. Incluem-se aí também as casas funerárias especializadas em cuidados com o corpo, com o cerimonial para receber os familiares enlutados e amigos. Como aponta Gurgel (2008), há mercantilização da morte, presente na sociedade ocidental. Todos os seres humanos vão morrer, portanto, nunca faltará emprego para os profissionais que realizam os cuidados com o corpo, os mais variados tipos de trabalho e alguns auferem grandes lucros.

Como é constrangedor quando se cobra por serviços funerários. Mas, por que não remunerar de maneira digna os profissionais que realizam trabalho tão essencial? Como diferenciar o que é justa remuneração e o que se torna abuso, aproveitar-se de pessoas em vulnerabilidade por estar sofrendo a dor da perda e extorqui-las.

Ariès (1977) aponta a desigualdade das formas de morte e rituais de acordo com classes sociais. Há a crença que quanto mais sofisticados os insumos e rituais mais parecem demonstrar respeito e amor pela pessoa perdida, configurando uma forma de garantia para o além, a salvação das almas. Essa crença pode ser utilizada de maneira mercantilizada por profissionais gananciosos, como se pode ver retratada na ficção, como já apontamos. Pode se observar também em produtos, como caixões feitos com materiais nobres, revestidos, com altura para acomodar a cabeça e uma campainha para aviso, caso a pessoa seja enterrada viva. No caso deste último item, sabemos que, com os atestados de óbito a probabilidade de enterrar vivos é nula.

Os profissionais funerários, a exemplo dos profissionais de saúde, também precisam, muitas vezes, esconder seus sentimentos, pois não se espera que se envolvam com os familiares ou com o falecido. Há expectativa de certo "profissionalismo", que o trabalho seja realizado com respeito, mas com dis- 
tanciamento, sem envolvimento com os sentimentos dos enlutados. A rotina de profissionais funerários é cuidar dos rituais após a morte, mas, precisam cuidar de pessoas enlutadas e ao mesmo tempo manter certa distância. A sociedade não espera que manifestem sentimentos e emoções no seu trabalho, mesmo quando se sentem tocados porque o morto lembra pessoas de sua família, ou situações vividas. Há delicada fronteira entre envolvimento, cuidado e distanciamento para que os agentes funerários possam dar conta de suas tarefas sem tanto sofrimento pessoal.

Entretanto, alguns casos mexem profundamente com os profissionais funerários, pelas circunstâncias da morte, por identificação com o falecido, com familiares, por ser criança ou jovem. Referem que quando o morto é criança precisam fazer o cerimonial com mais cuidado em consideração à família enlutada. Da mesma forma como ocorre com seus colegas da saúde, não há na instituição funerária lugar para cuidar daquelas perdas, que envolvem os sentimentos de seus profissionais. Acabam vivendo em si a solidão de uma dor e emoção não cuidadas. $\mathrm{Na}$ época de morte interdita, os rituais são minimizados, como já dissemos. No caso de profissionais funerários, há uma dupla interdição, a da morte e a deles, que têm seus sentimentos interditados para que se mantenha o chamado "profissionalismo". Eles não têm preparo para a realização das tarefas físicas, como cuidar dos corpos, cavar e construir os túmulos, só para citar algumas das atividades, e também para lidar com as questões emocionais envolvidas nos velórios, enterros e na aquisição dos serviços. Ouvindo as demandas dos profissionais durante os cursos, consideramos que eles precisam ter estratégias para realizar o acoIhimento do luto de pessoas em estado de choque com fortes sentimentos. Cabe discutir como seria esse preparo.
Com tantas questões e problemas com a profissão, perguntamo-nos o que faria pessoas escolher serem agentes funerários? Seria escolha, circunstância de vida ou não ter outro emprego? Seriam as vantagens de ser funcionário público? Eles têm conhecimento de todos os aspectos que estão relacionados com esse trabalho? Câmara (2011), em seu trabalho com agentes funerários em Natal no Rio Grande do Norte, traz no título a possível resposta: agente funerário, profissão que não se escolhe.

Em uma parceria estabelecida entre o Laboratório de Estudos sobre a Morte do Instituto de Psicologia da USP e o Serviço Funerário do Município de São Paulo (SFMSP), ministramos o curso "Morte e os Profissionais do SFMSP". Os profissionais desse serviço afirmaram que a escolha da profissão estava em ser funcionário público e não as especificidades do trabalho. Perguntamos aos profissionais, alguns com muitos anos de trabalho, próximos à aposentadoria, se novamente escolheriam essa profissão. Alguns deles afirmaram que aprenderam com a experiência e vêm sentindo importante significação na sua vida. Percebem que seu trabalho é essencial na vida das pessoas. Outros esperam se aposentar em breve. Essa reflexão nos permite pensar que, mesmo em uma profissão com tão poucos atrativos, pessoas podem encontrar um sentido maior, como o que se observa nos seus depoimentos e em filmes.

O filme A Partida (Takita, Japão, 2008) apresenta a história de Daigo Kobayashi, violoncelista que se vê desempregado e retorna à cidade natal assumindo um trabalho que facilita e embeleza partidas de pessoas, por meio do ritual de vestir, maquiar e acondicionar os corpos, a pedido de seus familiares, para que possam ter uma despedida digna. Torna-se assistente de um agente funerário, sem saber que terá de manipular corpos 
mortos (Site: www.adorocinema.com.br/filmes/filme-142464)

Vemos no filme como ele vai se acostumando com o trabalho que, a princípio, causa nojo e dificuldades. Gradativamente, vai se aperfeiçoando e encontrando a arte e o sublime no seu trabalho. Ao mesmo tempo em que dava alento e propiciava o último encontro da família com o falecido, provocava rejeição das pessoas de sua família, como a esposa, que ameaçou se separar dele, mas que gradativamente foi aceitando a nova profissão. O filme mostra também o quanto o trabalho de Daigo o aproximou do pai, com quem tivera uma relação muito difícil na infância. Observa-se o quanto se desenvolve como pessoa, à medida que vai se aperfeiçoando na arte do seu trabalho. O grande mérito desse filme, embora realizado na cultura oriental, é trazer ao grande público a importância do trabalho funerário e seu alcance para que os que dele usufruem.

Saporetti (2012) ${ }^{1}$, ao debater o filme, apresentou quatro pontos de discussão: a) busca de sentido da vida ao realizar o trabalho, que é difícil a princípio e faz com que entre em contato com seus sentimentos: a arte de ver sentido de uma vida em um corpo morto, tornando sagrado esse momento da existência; b) importância dos ritos mortuários, destacando seu valor simbólico para além do ato em si, resgatando imagens do inconsciente, da transcendência e valor terapêutico, a preservação da identidade para além da morte. Infelizmente, atualmente esse elemento está sendo perdido; c) dignificação e transcendência da morte ao tornar o ritual de preparação do corpo um momento especial, como se observa quando Daigo realiza o ritual de preparação com o corpo do pai; d) resgate da imagem do pai. É um filme que trata o tempo todo de morte e tão pleno de vida como é o resgate da relação com o pai, que foi tão difícil durante toda a vida. É um filme que fala de encontros e reencontros.

Seria muito interessante trazer esse filme para debate com profissionais de funerárias. Como um trabalho tão rejeitado pela sociedade, familiares e também pelo próprio profissional pode trazer um sentido tão profundo para a vida?

Esse filme traz a questão como a escolha da profissão nem sempre envolve o conhecimento de suas características, o que também está presente no depoimento dos profissionais. A primeira ou outras experiências podem ser marcantes por várias circunstâncias, pelo horror do corpo em decomposição, por sentimentos ambivalentes e intensos dos familiares, pelas circunstâncias da morte, por questões pessoais e experiências vividas pelos agentes funerários. O odor forte é uma situação muito associada a essa profissão, nas suas várias atividades. É uma mistura de cheiros: flores, velas, elementos químicos para preservação do corpo, mas, sem dúvida, o pior é o cheiro do corpo morto.

Como cuidar de pessoas que vivem uma profissão tão insalubre? Farina et al. (2009) apontam que os profissionais têm uma profissão com tantas cargas: física (trabalho pesado, com odor fétido e risco de contaminação; psíquica (dor, sofrimento, sentimentos intensos, os próprios e dos enlutados); social (baixa remuneração, profissão não reconhecida, com baixo prestígio). Há risco para o próprio profissional e para a família.

\section{Uma aproximação da experiência (ou do cotidiano) dos trabalhadores da morte}

Em 2010-2011, o Laboratório de Estudos sobre a Morte promoveu cursos com o tema "Morte e os profissionais do Serviço Funerário do Município de São Paulo (SFMSP). O 
curso, com oito horas de duração, incluiu os seguintes temas: 1) Morte e fases do desenvolvimento: crianças, adolescentes, adultos e idosos; 2) Morte inesperada: violência, trauma, suicídio. Morte "esperada": doenças; 3) Processos de luto. Rituais. Abordagem familiar; 4) Cuidando do profissional do Serviço Funerário. O curso foi oferecido em dois dias e cada tema foi acompanhado de tempo para questões e discussão.

A proposta do curso foi o aprofundamento de questões psicológicas para profissionais que trabalham com a morte no seu cotidiano. A demanda do curso teve origem na necessidade desses profissionais para cuidados psicológicos e foi um impulso inicial para esse cuidado. Procuramos trazer conteúdo informativo, um tempo para perguntas e incentivamos as de ordem pessoal. Ressaltamos que não há perguntas erradas e também que respostas simplistas poderiam induzir a erro. Buscamos facilitar a emergência de questões emocionais envolvidas no contato com familiares que perderam recentemente seu ente querido.

Participaram do curso funcionários do Serviço Funerário do Município de São Paulo, entre os quais sepultadores, veloristas, motoristas, funcionários do serviço administrativo, prestadores de serviços a esta instituição.

\section{Serviço Funerário Município de São Paulo - seus profissionais e a questão da morte}

As informações que apresentamos a seguir foram fornecidas por Vanuzia Ribas e Francisvaldo Gomes, funcionários do Serviço Funerário do Município de São Paulo (2012).

A partir de 1958, por meio da Lei no 5.562, o Serviço Funerário do Município de São Paulo (SFMSP) foi transformado em autarquia, sendo caçadas todas as licenças para empresas "terceirizadas".

Desde então, o SFMSP detém a competência exclusiva para a realização dos serviços de traslados, velórios e sepultamentos de óbitos ocorridos na cidade de São Paulo, velados e sepultados nos cemitérios municipais e/ou particulares, além da remoção de corpos para o Serviço de Verificação de Óbito (SVO) do Hospital das Clínicas de São Paulo. O SFMSP atua nos seguintes segmentos:

- Rabecão (RECORPS), remoção de corpos para verificação de óbitos por morte natural (S.V.O);

- Agências de Contratação de Funeral 14 Agências para atendimento, instaladas em pontos estratégicos da cidade para facilitar o acesso dos munícipes;

- Remoção - 50 viaturas e 191 motoristas para executar o transporte dos corpos para velórios, cemitérios e remoção para fora do município;

- Enterro - 22 Cemitérios distribuídos na capital e 01 crematório municipal;

- Velórios - 18 dependências/unidades com 116 salas, junto aos cemitérios municipais;

O Serviço Funerário do Município de São Paulo conta com 1.390 servidores, entre efetivos, comissionados e admitidos para comportar a demanda dos serviços prestados à população de São Paulo. Esses são os números e os fatos desse serviço.

No entanto, a mídia, por vezes, apresenta visão muito negativa do SFMSP, por entender que seus profissionais sejam mercenários, só realizando o trabalho mediante uma "caixinha". É importante ressaltar, como apontam Ribas e Comes (2012), que essa não é a representação da maioria dos funcionários do serviço.

Problemas familiares enlutados se manifestam aos profissionais funerários como brigas do casal, 
questões de herança e divergências quanto a como realizar o trabalho. Essas são situações que causam constrangimento e estranhamento e é difícil seguir com o trabalho.

Uma queixa muito frequente dos usuários se relaciona com o tempo necessário para que se desenrolem os trâmites administrativos e funerários, e a família, que está transtornada e se sente desrespeitada. Segundo Ribas e Gomes (2012), são atacados principalmente os sepultadores. Nesse momento, qualquer burocracia ou ocorrência que vier a causar desgaste pode gerar tumulto e revolta nos familiares.

No texto: Trabalhadores da morte - dilemas éticos (2012), Francivaldo Almeida Gomes (conhecido como Popó) relata seu trabalho como sepultador. Atualmente, tem como função apresentar a arte tumular presente no Cemitério da Consolação, contando a história da cidade de São Paulo, por meio dos personagens lá enterrados. São frequentes as visitas de crianças de escolas públicas e privadas, devendo-se ressaltar o programa "Amigos do Zippy"2, em que crianças visitam cemitérios como forma de educação para morte, desmistificando o tabu, aprendendo a compreender um ritual tão pouco valorizado na sociedade atual.

\section{Demandas e cuidados}

Perguntamos o que os funcionários participantes buscaram no curso e as respostas puderam ser organizadas nas seguintes categorias principais: a) conhecimento e aprendizagem sobre tema da morte e luto; b) como lidar com famílias enlutadas, principalmente quando ocorrem mortes violentas; c) conhecer problemas psicológicos, principalmente a depressão e possibilidades de cuidados, entre os quais a psicoterapia; d) formas de lidar com familiares em situação de crise, com ansiedade e outros sentimentos. Questões como melhorias de salário e condições físicas foram contextualizadas como busca pessoal e sobre a qual não poderíamos interferir.

Há profissionais que veem o curso como forma de cuidado. Permitiu também que conhecessem a experiência de colegas, daqueles que exercem a mesma função ou outras. Alguns relataram que a possibilidade de saber que há uma equipe faz com que se sintam menos isolados e possam assim compreender os colegas.

A morte faz parte do cotidiano desses profissionais, mas é vista por eles de forma bem particular. É vista como evento natural e, para outros, carregada de sentimentos. Além da dimensão pessoal, a morte é vista como instrumento de trabalho. Se não houvesse mortos, não haveria razão para a sua profissão. Há aqueles que acreditam que não devem se deixar envolver por questões pessoais. Mas, eles mesmos se questionam, é possível? Por um lado, defendem o sangue frio para enfrentar situações difíceis, por outro, se ficam muito distantes, podem ser considerados desumanos ou cruéis. Perguntam se há formas adequadas para lidar com familiares enlutados? Sabem que situações de morte e formas de enfrentamento são muito diversas e as necessidades podem variar muito. Alguns deles pensam que precisariam separar as emoções para se tornarem profissionais meIhores. Apontam que o mais difícil do seu trabalho é cuidar de pessoas enlutadas nesse momento de sua vida.

Os profissionais ressaltam que seu trabalho não é reconhecido e esperam que, a partir de cursos como o acima mencionado, seu trabalho possa ser valorizado. Puderam entrar em contato com a morte em outras culturas, relataram situações em que observaram rituais diferentes dos que estão habituados. Esses pontos enriquecem o seu trabalho, pois permitem que pessoas possam ter lembran- 
ças especiais de seus entes queridos. Então, os profissionais funerários não trabalham somente com perdas e sim com questões fundamentais da existência humana, ligadas à elaboração do luto após a morte de pessoas significativas.

Desenvolvemos, no curso, a reflexão de que os profissionais das funerárias são vistos como cuidadores, que assim se sentiram identificados e valorizados com esse significado do trabalho. Percebem-se responsáveis como funcionários públicos tendo de cuidar do bem-estar do munícipe.

Alguns profissionais gostariam de aperfeiçoar sua relação com as pessoas que atendem. Querem ser empáticos, colocar-se no lugar daquele que sofre a perda de seus entes queridos. Buscaram o curso e o contato com psicólogos como estímulo para se tornarem cuidadores. Entendem que precisam se conhecer melhor e o que viram no curso pode ser transferido para as relações familiares e vida pessoal.

Muitos profissionais relataram que eles e seus colegas convivem com estresse prolongado, entram em colapso e consomem álcool como válvula de escape. Quando falamos sobre a síndrome laboral de burnout, verificamos que não tinham conhecimento do termo, mas, ao apresentarmos os sintomas, imediatamente os reconheceram. Admitiram limites para o que podem suportar e os índices de tolerância podem ser diferentes de pessoa para pessoa. Puderam também compreender o que são situações que podem se modificar por estratégias pessoais e as que dependem de uma equipe de trabalho, da chefia ou da instituição. Podem se posicionar como vítimas ou agentes. Como aponta Farina et al. (2009), a relação que estabelecem com o trabalho é fundamental para a sua adaptação e enfrentamento da realidade.
Houve profissionais que relataram a necessidade de cuidados psicológicos e queriam compreender como funciona a psicoterapia. Queriam entender melhor o que seriam os cuidados psicológicos, nas suas várias opções. Gostariam que o Serviço Funerário de São Paulo providenciasse esse cuidado. Houve profissionais que entenderam o curso como lugar de cuidado para si próprio, como um deles mencionou um "oásis psicológico".

A partir das respostas dadas pelos profissionais do Serviço Funerário de São Paulo, estamos planejando propostas de cuidados a esses funcionários a partir das necessidades expressas durante os cursos ministrados. Entre elas: novos cursos, workshops, supervisão, plantão psicológico e psicoterapia. Os cuidados podem ser de ordem pessoal ou institucional, individual ou em grupo. Em um primeiro momento, partirão da parceira com o Laboratório de Estudos sobre a Morte e, posteriormente, oferecendo subsídios para que o próprio SFMSP possa criar seu serviço de cuidados psicológicos alojado na instituição.

\section{Considerações finais}

Podemos olhar para esses funcionários como cuidadores de pessoas, de corpos mortos e de familiares enlutados, que assim podem ter a possibilidade de velar e guardar boas memórias, como aponta Câmara (2011). São cuidadores do final da vida. O trabalho de agentes funerários está ligado também à boa morte, uma vez que são os que oferecem os insumos e também promovem a disposição do corpo, abrem as covas, realizam a construção de túmulos. Estes são os locais onde os mortos serão reverenciados e que podem deixar boas lembranças. Assim, como há a reumanização do processo de morrer para pacientes gravemente enfermos (Kovács, 2003), poderemos pensar de maneira similar na reumanização nos rituais 
expressos na forma de lidar com o corpo morto, resgatando-se a subjetividade daqueles que se despedem das pessoas queridas. Assim, transforma-se o defunto na pessoa amada, diminui-se o lugar de interdito dos rituais em relação à partida do falecido e às memórias do enlutado. $O$ filme $A$ Partida aborda essa questão com muita delicadeza. Resgatar o valor, significado e emoção do trabalho funerário é uma forma de humanização e cuidado e também pode ser estratégia de prevenção do burnout. Agentes funerários relataram o agradecimento de familiares que tiveram seus rituais acompanhados de respeito, emoção e cuidado. Isso pode se refletir em uma conversa cuidadosa no momento de contratação dos serviços funerários, transporte do corpo, sepultamento ou cremação.

Como toda profissão, a criatividade é possível, inovando-se na forma de realizar a ação nos vários rituais oferecidos. Muitos profissionais se queixam de não estarem preparados para o seu trabalho. Mas, será que querem de fato se preparar e buscar novos conhecimentos e realizar o trabalho com sentido pessoal? Afirmam ter maior dificuldade para lidar com a morte em relação a pessoas vivas. Cuidam de corpos mortos, aprendem técnicas de cavar covas, abaixar caixões, preparar para cremação. É uma profissão que toca a morte na sua concretude. Mas, não sabem o que fazer com a morte em vida, com familiares enlutados, com as fortes emoções daqueles que sofrem com a perda. Muitas vezes, atendem pessoas em choque, transtornadas. Os profissionais funerários que mais sofrem esse tipo de situação são aqueles que atendem na contratação dos rituais e insumos. Por fim, o seu trabalho é apreciado e reconhecido por vivos, por aqueles que recentemente perderam pessoas queridas. É considerado cuidado possível na vida ausente.

Como cuidar desses profissionais, quais são seus mecanismos de enfrentamento? Como relaxam? Como cuidam de seu sofrimento? Que atividades buscam para si, o quanto a instituição deve colaborar nesse processo, que espaços de cuidados devem ser oferecidos? Como seu trabalho deve ser reconhecido por eles, pelos colegas, pelas instituições, pelos usuários e pela sociedade? Como se adaptam a uma profissão que para ganhar a vida trabalha-se com a morte?

Observamos que quando se dá voz a esses profissionais, falam com emoção de sua experiência. Como falar sobre a morte para profissionais que lidam cotidianamente com ela? O tempo de serviço ajuda nas formas de enfrentamento pelas experiências vividas, mas não os protege de todas as situações. 


\section{Maria Julia Kovács}

Doutora em Psicologia Escolar e do Desenvolvimento Humano pela Universidade de São Paulo, São Paulo - SP. Brasil. Docente da Universidade de São Paulo, São Paulo - SP. Brasil.

E-mail: mjkoarag@usp.br

\section{Nancy Vaiciunas}

Graduada em Psicologia pela Universidade de São Paulo, São Paulo - SP. Brasil.

E-mail: sandias@usp.br

\section{Elaine Gomes Reis Alves}

Doutora em Psicologia Escolar e do Desenvolvimento Humano pela Universidade de São Paulo, São Paulo - SP. Brasil.

E-mail: elainegralves@gmail.com

\section{Endereço para envio de correspondência:}

Laboratório de Estudos sobre a Morte. Departamento de Psicologia da Aprendizagem, do Desenvolvimento e da Personalidade. Instituto de Psicologia USP. Av. Mello Morais, 1721 - Cidade Universitária. CEP: 05508-900. São Paulo - SP. Brasil.

Recebido 23/04/2013, 1a Reformulação 16/01/2014, Aprovado 29/09/2014. 
Ariès, P. (1977). História da morte no Ocidente. Rio de Janeiro, Zahar.

Câmara, M. C. C. (2011). O agente funerário e a morte. O cuidado presente diante da vida ausente. Dissertação de mestrado. Programa de Pós-Graduação em Psicologia. Universidade Federal do Rio Grande do Norte, Natal, RN.

Dittmar, W. H. (1991). Um estudo sobre a prevalência de distúrbios psiquiátricos entre os sepultadores do Serviço Funerário Município de São Paulo. Dissertação de Mestrado. Faculdade de Medicina da Universidade de São Paulo, São Paulo SP.

Elias, N. (2001). A solidão dos moribundos. Rio de Janeiro: Zahar.

Farina, A. S., Antunes, A. D. A. Yokomizo, J. E., \& Ariente, L. A. (2009). A morte como trabalho, um estudo com agentes funerários da Grande São Paulo. In A. M. Carvalho, A. S. Farina, E. M. Franco, C. Stella, J. Garção, R. S, Rusche, \& V. Siqueira (Orgs). Temas contemporâneos em Psicologia do Cotidiano (pp. 35-58). São Paulo: Editora Expressão e Arte.

Feifel, H. (1959). The meaning of death. New York: Mac Graw

Glaser, B. G. \& Strauss. A.L. (1966) Awareness of dying. New York: Transaction Publishers.

Gurgel, A. (2008). Direitos sociais dos moribundos. Controle social e expropriação da morte. São Luís, MA: Editora da Universidade Federal do Maranhão.

Kastenbaum R, \& Aisenberg, R. (1983) Psicologia da Morte. São Paulo: Pioneira

Kovács, M. J. (2003). Educação para a morte. Temas e reflexões. São Paulo: Casa do Psicólogo.
Kovács, M.J. (2008). Desenvolvimento da tanatologia. Estudos sobre a morte e morrer. Paidéia, Ribeirão Preto, SP, 18, 457-468. doi: http://dx.doi.org/10.1590/S0103863X2008000300004

Ribas, V., \& Gomes, F. A. (2012). Trabalhadores da morte. Dilemas Éticos. Mundo da Saúde, 36(1), 86-89. Recuperado de http://www.saocamilosp.br/pdf/mundo_saude/90/12.pdf

Prefeitura do Munícipio de São Paulo, (1958). Lei 5562 de 1958. Reorganiza sob forma autárquica o Serviço Funerário do Munícipio de São Paulo, e dá outras providências. São Paulo, SP: Autor. Recuperado de https://www.leismunicipais.com.br/a/sp/s/saopaulo/lei-ordinaria/1958/557/5562/lei-ordinari a-n-5562-1958-reorganiza-sob-formaautarquica-o-servico-funerario-do-municipiode-sao-paulo-e-da-outras-providencias

Saporetti, L. (2012). A partida. éticos. Mundo da Saúde, 36(1), 133-135. Recuperado de http://www.saocamilosp.br/pdf/mundo_saude/90/20.pdf

Schneidman, E. \& Faberow, N. (1959). Suicide and death. In Feifel, H. (Edit.) - Meanings of death. (pp. 284-299). New York: Mc Graw Hil.

Souza, K. C .C., \& Boemer, M. R. (1998). O significado do trabalho em funerárias sob a perspectiva do trabalhador. Saúde e Sociedade 7(1), 27-52. doi: 10.1590/S010412901998000100003

Takita, Y. (Diretor). (2008). A Partida. Japão. Recuperado de http:// www.adorocinema.com./filmes /filme 142464)

Trapero, P. (Diretor). (2010). Abutres [Filme]. Argentina/Chile. Recuperado de http://www.adorocinema.com/filmes/filme180376. 